\title{
ESCRAVIDÃO, PÓS-ABOLIÇÃOO E A POLÍTICA DA MEMÓRIA
}

MATTOS, Hebe; ABREU, Martha (orgs.). Passados presentes. Rio de Janeiro: Laboratório de História Oral e Imagem, Universidade Federal Fluminense (LABHOI/UFF), 2005-2011. Coletânea de quatro DVDs. Apoio: Editora da UFF, FAPERJ, CNPq e Petrobras.

$N_{\text {o campo da historiografia do ne- }}$ gro no Brasil, a transição da escravidão para a emancipação e o período pós-Abolição talvez sejam das áreas que mais vitalidade adquiriram na última década. Uma expressão dessa tendência é a coletânea Passados presentes, uma série de quatro documentários sobre as trajetórias, memórias e práticas culturais dos descendentes dos escravizados na região da antiga província do Rio de Janeiro. Os quatro filmes, intitulados Memórias do cativeiro: familia, trabalho e cidadania no pós-Abolição (2005), Jongos, calangos e folias: música negra, memória e poesia (2007), Versos e cacetes: o jogo do pau na cultura afro-fluminense (2009) e Passados presentes: memória negra no sul fluminense (2011), foram produzidos pelo Laboratório de História Oral e Imagem da Universidade Federal Fluminense (LABHOI/UFF), sob a direção geral das historiadoras Hebe Mattos e Martha Abreu. ${ }^{1}$ Lançada em 2012, a coletânea

Os trabalhos estão disponíveis no site $<$ http:// www.labhoi.uff.br/passadospresentes/>. reúne trabalhos produzidos ao longo de mais de seis anos, a partir do acervo audiovisual do LABHOI, que hoje conta com cerca de 300 horas de gravações. O primeiro filme, Memórias do cativeiro, utiliza, entre outros, registros de entrevistas com descendentes de escravos africanos gravadas em São Paulo, em 1987, e no Rio de Janeiro e Espírito Santo nos anos de 1994 e $1995 .^{2}$ Porém, o conteúdo substancial da série está baseado em registros videográficos mais recentes, produzidos, na sua maioria, na primeira década deste século, no estado do Rio de Janeiro, e constitutivos do Acervo UFF Petrobrás Cultural - Memória e Música Negra, principal base documental da série. ${ }^{3}$

\footnotetext{
As entrevistas de 1987 se originam do projeto Memória da Escravidão em Famílias Negras de São Paulo, desenvolvido na USP. As entrevistas de 1994 e 1995 são parte do projeto Memória, Escravidão e Cidadania, desenvolvido pelo LABHOI, sob a direção de Hebe Mattos.

3 O catálogo deste acervo está disponível online: $<$ http://www.historia.uff.br/jongos/acervo/ index.php $>$. Trata-se de um dos produtos do projeto Jongos, calangos e folias: música negra, poesia e memória, realizado com o apoio do Edital Petrobrás Cultural, 2005.
} 
A temática geral da coletânea se insere no âmbito dos estudos sobre a cultura popular e a tradição oral das populações afrodescendentes. Seus principais eixos narrativos examinam

[...] as relações entre memória, escravidão e formas de pertencimento e cidadania. [...] abordam as releituras políticas da memória da escravidão no tempo presente, e a memória da escravidão enquanto presença do passado nas trajetórias de vida dos libertos e seus descendentes. ${ }^{4}$

Para além desse foco na política da memória, consoante com o espírito do LABHOI, a coletânea é inovadora na sua tentativa de desenvolver formas de narrativa historiográfica a partir de uma escrita audiovisual.

Como os quatro documentários têm por base o mesmo acervo documental, várias personagens aparecem de forma reiterada, conferindo ao conjunto uma relativa unidade. Por exemplo, o entranhável senhor Manoel Seabra, nascido em 1919, liderança da comunidade da antiga Fazenda São José da Serra, no município de Valença, no Vale do Paraíba - hoje Quilombo de São José - aparece, no primeiro filme, rememorando seus ancestrais africanos, vindos da Bahia; no segundo, dançando o jongo; e, no terceiro, praticando o jogo do pau. O senhor

4 Texto introdutório do eixo temático "Memória, África, Escravidão" do LABHOI, $<$ http://www.labhoi.uff.br/escravidao $>$.
Manuel Morais, líder da comunidade do Quilombo de Santa Rita do Bracuí, aparece também em diversos momentos. Assim, embora os documentários tenham sua autonomia, acabam por oferecer uma visão multifacetada e polifônica de uma mesma realidade sociocultural.

Como se sabe, a presença contemporânea de famílias afrodescendentes na região sudeste do estado do Rio de Janeiro é, em grande medida, resultado histórico do recrutamento massivo de mão de obra escravizada, em meados do século XIX, para satisfazer a demanda da economia do café. No Vale do Paraíba, concretamente, nesse período, os africanos chegaram a constituir $90 \%$ da população. As falas, recordações, práticas culturais e ação política dos descendentes desses escravizados são o alvo prioritário de reflexão historiográfica da coletânea em questão.

O primeiro filme, Memórias do cativeiro $(2005,43 \mathrm{~min}$.) teve o seu roteiro baseado no livro Memórias do cativeiro: familia, trabalho e cidadania no pós-Abolição (Niterói: Civilização Brasileira, 2005), de Hebe Mattos e Ana Lugão Rios, livro que focaliza no que Rios chamou de "campesinato itinerante", destacando

[...] a importância da família e da mobilidade como elementos constituintes da ética de trabalho que marcara a inserção social dos libertos do Sudeste após a abolição". 5

5 Monica Grin e Hebe Mattos, "Para Ana Lugão (1960-2012)", Topoi, v. 13, n. 24 (2012), p. 8. 
Conforme o título do livro, a memória da escravidão, a família, o trabalho e a luta pela cidadania constituem também os principais temas da narrativa videográfica.

O filme apresenta uma concatenação bastante eclética de depoimentos de indivíduos de diversas regiões do Rio de Janeiro, do Espírito Santo e de São Paulo, falas intercaladas com interlúdios musicais e cartazes com títulos e breves textos que pautam as principais seções da narrativa. A parte das entrevistas, gravadas nas décadas de 1980 e 1990, foi realizada apenas com áudio (às vezes de qualidade precária). Por isso, as vozes, sempre legendadas, são acompanhadas, num tratamento visual bastante convencional, por imagens fixas, como iconografia da escravidão ou manuscritos, e com imagens em movimento de fazendas, senzalas ou instrumentos de castigo. Um pouco mais original resulta a leitura feita, em 2005, por membros do Quilombo São José, das transcrições das entrevistas realizadas em São Paulo, em 1987.

Os mais velhos dos depoentes nasceram nas primeiras duas décadas do século XX, e suas falas evocam memórias de seus pais, avós e bisavós, ou seja, de duas a três gerações prévias, remontando cronologicamente a meados do século XIX, na época dos últimos escravizados africanos e de seus filhos e netos nascidos no Brasil. Apesar da variedade regional dos entrevistados, os testemunhos orais estão organizados seguindo uma cronologia historiográfica. $\mathrm{O}$ filme se inicia com as memórias mais longínquas da África, passando logo ao tempo do cativeiro, depois ao tempo da liberdade, até chegar aos quilombos contemporâneos.

Se a memória da África é genérica e imprecisa, quase mítica, as recordações do tempo do cativeiro são mais vívidas, embora não isentas de convencionalismos. Várias falas reiteram um contraste entre um antepassado 'escravo' e 'estrangeiro' e seus filhos 'brasileiros', quase sempre lembrados como 'ventre livres'. A divisão entre o tempo do cativeiro e o tempo da liberdade, marcada pela Lei de 1871 e a Lei Áurea de 1888, constitui uma descontinuidade crítica na periodização dessa memória. As experiências dos avós e bisavós escravos se opõem às dos filhos libertos a partir do ventre livre. Também o 13 de maio, com lembranças de fugas em massa, é valorizado pelos mais velhos como momento emblemático de transformação em que os negros passaram a ser senhores do seu próprio destino.

A memória do cativeiro é geralmente silenciada, mas, quando aflora, ela afirma sua realidade — "ele foi escravo verdadeiro", diz um dos depoentes. Lembram-se os comboios que transportavam os cativos e de sua venda no leilão _ " "quem tinha a perna mais fina valia mais". Esse tempo vem marcado, sobretudo, pela memória do castigo, da violência exercida sobre o corpo 
escravizado, do poder e da crueldade senhoriais. Casos de punições exemplares são reiterados, porém as atrocidades, sempre contadas por "ouvir dizer", nunca se referem a parentes do narrador. As vítimas são sempre "outros". A essa memória do castigo se une a da resistência, das fugas, dos ardis para escapar do controle senhorial. Os poderes sobrenaturais dos africanos, por exemplo, são evocados como expressão da vitória simbólica do oprimido sobre o opressor.

Nesse contexto de adversidade, os "Laços de família", título da terceira seção do filme, constituíam os elos primários do tecido social, responsáveis, em última instância, pela sobrevivência do grupo. A crescente importância conferida pela historiografia à família escrava encontra um paralelo na lembrança recorrente dos depoentes das genealogias e dos nomes dos antepassados, como mnemotécnica fundamental na imaginação das origens e da identidade coletivas. Por isso, a memória da ruptura das famílias, com a separação de crianças gerada pelo tráfico interno, resulta tão traumática. Associada à valorização do parentesco e à ancestralidade, há também, em algumas falas, uma ênfase na boa reputação, numa ética do trabalho como forma de romper com a violência da escravidão, de superação das adversidades e de inserção social.

A última seção do documentário, intitulada "Diálogo dos tempos" aponta para importantes reflexos, operados na memória, entre o tempo da escravidão e o tempo dos fazendeiros, no pós-Abolição. Se o controle sobre o trabalho familiar define o tempo da liberdade, o poder abusivo dos fazendeiros estabelece continuidades com o tempo do cativeiro. Se a economia de subsistência da roça substituiu a economia escravocrata dos cafezais, a emergência do gado e da urbanização coloca novos desafios. As memórias do tempo do cativeiro e do tempo da liberdade parecem se retroalimentar e se moldar mutuamente. Esse jogo de espelhos se manifesta, por exemplo, na figura de Getúlio Vargas, lembrado como libertador e defensor dos direitos trabalhistas do campesinato negro, e, por isso, reverberando a imagem da princesa Isabel, mas também a nova consciência dos direitos de cidadania contemporâneos.

O documentário finaliza com imagens das festas do 13 de maio de 2005 no Quilombo de São José. Essa celebração, hoje ressignificada pelo discurso dos movimentos negros, para além da festa da abolição, como homenagem aos pretos velhos, envolve muita comida e a dança do jongo. Destaca-se, neste epílogo, como uma prática cultural originária do tempo do cativeiro serve hoje para a afirmação política. Ou seja, a ligação com o passado resulta instrumental para a luta do presente, do mesmo modo que o presente molda as possibilidades de imaginar o passado. Nesse sentido, a atuação da memória na experiência do presente - o passados presentes que intitula e perpassa toda a coletâ- 
nea - estabelece uma clara continuidade com o segundo filme.

Jongos, calangos e folias: música negra, memória e poesia (2007, $48 \mathrm{~min}$.) focaliza, precisamente, o passado e o presente dessas práticas culturais nas comunidades negras do estado do Rio de Janeiro e na centralidade que nelas assume a poética do canto. Novas recordações dos tempos do cativeiro e lembranças de como eram praticadas essas festas no passado misturam-se com relatos sobre a sua vigência, transformações e importância política contemporâneas.

Contrariamente ao primeiro filme, onde prevalece certa dispersão geográfica, houve neste segundo uma tentativa de pautar a narrativa a partir de um itinerário espacial. A primeira parte centra-se no litoral, nas comunidades quilombolas do Bracuí, em Angra dos Reis, e Rasa, em Búzios, lugares de desembarque de escravos. A segunda parte sobe a Serra do Mar, chega ao Vale do Paraíba, onde estavam as grandes plantações de café no século XIX, apresentando as comunidades de Barra do Piraí, Quilombo São José e Duas Barras. A terceira parte desce a serra até a Baixada Fluminense, especialmente Nova Iguaçu, Mesquita, Duque de Caxias e São João do Meriti,

[...] para onde muitos dos descendentes dos últimos escravos se dirigiram, em diferentes momentos do século XX, na busca por melhores oportunidades de trabalho.

Ou seja, acompanhando o per- curso espacial, segue-se, como no primeiro filme, uma cronologia historiográfica que se inicia com a chegada dos escravos no litoral, passa pela escravidão no interior e finaliza no período pós-Abolição. Contudo, devo registrar que precisei ver mais de uma vez o documentário e de ler o catálogo que o acompanha para discernir essa lógica estrutural.

A sequência de entrevistas com afrodescendentes tem por contraponto, nessa ocasião, alguns depoimentos de acadêmicos, de modo que o discurso verbal continua a reinar soberano. Porém, pela temática abordada, o filme utiliza com maior proeminência imagens da performance de jongos, calangos e folias de reis, embora, na minha opinião, de forma episódica e ilustrativa. Nas danças e na gestualidade desses rituais se inscreve uma memória corporal talvez negligenciada pelos autores, mas os registros contêm um rico acervo de músicas e cantos que conferem ao documentário um valor etnográfico singular, não apenas pelo conteúdo verbal, mas também pela performance interpretativa.

Herança e memória do passado, o patrimônio poético dessas manifestações mostra a centralidade que a oralidade e a palavra têm na cultura dessas comunidades rurais negras. A criatividade manifesta no uso da metáfora, do subentendido, da alusão oblíqua nas cantigas, é tributária de um talento linguístico e de uma tradição oral que o filme tem o mérito de destacar. Nesse acervo poético/musical, aparece codifica- 
da, de novo, a memória da Guiné, de Angoma, da escravidão, da emancipação e da afirmação identitária: "sou negro, sim senhor, filho de Moçambique".

Nessa prática discursiva, a improvisação se constitui como um dos recursos performáticos mais valorizados. O improviso adquire especial destaque nos desafios, aspecto marcante dos jongos e calangos. Trata-se de disputas poéticas em que um puxa uma cantiga, e um segundo deve responder com outra, "mas não pode sair do ritmo, tem que ser na escala". Nessa troca, surge a provocação, o deboche, a brincadeira, ou o abuso, e não era infrequente acabar em briga. No calango, celebrado dentro da casa, com sanfona, pandeiro e "baile", o desafio é geralmente rimado, e quem responde deve iniciar com o último verso do primeiro cantor. $\mathrm{O}$ jongo, por sua vez, celebrado ao ar livre, em volta da fogueira, ao som do caxambu ou tambu, com dança por pares, envolve outro protocolo e hierarquia. Como aponta o historiador Robert Slenes, jongo significaria "palavra bala". No jongo de demanda, que as crianças não podiam frequentar, os jongueiros velhos puxavam pontos que faziam sumir as pessoas ou madurar uma bananeira da noite para o dia, trocas cheias de mistério, em que, no passado, "saía de tudo, até briga".

Também as folias de reis, em volta dos presépios, com suas bandeiras, caixas e danças, superpõem o sagrado e o profano. A partici- pação na brincadeira da Epifania pode responder a promessas a São Sebastião ou aos Santos Reis, mas esses elementos do catolicismo popular incorporam as mascaradas de sabor africano dos palhaços, metendo medo e também puxando versos e cantigas. $\mathrm{O}$ documentário mostra como os praticantes da folia preservam estórias secretas do rei Gaspar, o rei negro que, discriminado pelos reis brancos, chegou não obstante antes deles ao presépio. Ou seja, as práticas culturais codificam discursos ocultos que contestam as narrativas hegemônicas e que expressam leituras críticas da problemática racial.

Assim, as três manifestações culturais - jongos, calangos e folias - constituem patrimônios culturais associados à história social das famílias que lhes dão suporte e, portanto, apresentam variações regionais difíceis de serem sistematizadas. Há implícita no filme uma lógica de caráter difusionista que pressupõe um deslocamento das manifestações acompanhando as migrações de seus praticantes, embora as folias de reis da Baixada Fluminense apresentem múltiplas origens, não apenas do estado do Rio de Janeiro. Desse movimento, resultam intrincados processos de apropriação e mistura em que os palhaços das folias, por exemplo, se engajam em desafios próprios dos calangos e dos jongos. O problema antropológico da continuidade entre formas culturais e suas transformações emerge na última parte do 
documentário. No litoral, o jongo, antes discriminado como macumba, hoje é valorizado como cultura pelos movimentos negros, ao tempo em que pastores evangélicos compõem para suas cerimônias músicas no ritmo de jongo. Como no primeiro filme, o encerramento traz imagens da luta política contemporânea, com discursos das lideranças do Quilombo de São José reivindicando o papel do jongo na legitimação política das comunidades remanescentes de quilombo.

A direção e o roteiro do terceiro filme, Versos e cacetes: o jogo do pau na cultura afro-fluminense (2009, 38 min.) está assinada por Matthias Röhrig Assunção e Hebe Mattos. Como indica o título, a narrativa do filme avança do verso, com a apresentação da disputa simbólica travada no desafio do calango, para o cacete, a briga física do jogo do pau, uma mistura de dança e luta culturalmente estilizada que apresenta alguma semelhança com a capoeira. A afrogeografia explorada continua a ser o Quilombo São José e Vassouras, no Vale do Paraíba, e a comunidade de Duas Barras e Miracema, no noroeste fluminense.

A primeira parte do filme recria o ambiente das festas de calango já tratadas no segundo filme, evocando os bailes celebrados nas fazendas e os versos dos desafios que, embora originalmente improvisados, se preservam na memória com tenacidade. Desses bailes participavam pessoas vindas de fora, de fazendas ou povoados vizinhos, com as quais se travavam os desafios verbais. Quem perdia era vaiado e, frequentemente, após a meia-noite, com os efeitos do álcool, "o couro comia", com enfrentamentos a golpes de cacete ou rasteiras. Expressão das tensões e rivalidades locais, essas brigas faziam parte do cotidiano rural. Contudo, o cacete era também usado numa brincadeira amistosa, praticada aos domingos, chamada jogo do pau, jogar cacete, jogar pau, bater pau etc., o cerne temático do documentário. Röhrig Assunção, que é também historiador da capoeira, sustenta que essa tradição de jogo de combate, praticado no meio rural das fazendas, pode ajudar a compreender a história da capoeira, geralmente associada às zonas portuárias das cidades.

O filme documenta as diversas técnicas, a forma de segurar o cacete com duas mãos, os passos, fintas, rasteiras, pernadas, ou "rabo de arraia", movimentos de defesa que exigem reflexos rápidos e a contorção do corpo para se esquivar do golpe, mas também a imprescindível ginga para enganar e atacar. Aparece de novo a importância da família na transmissão desse conhecimento, passado de pais a filhos, praticado com irmãos e primos, mas ficando evidente a progressiva perda de um patrimônio que hoje só os mais velhos ainda lembram.

Coloca-se de novo a questão das continuidades culturais, a relação do jogo do pau com outras variantes do folclore regional (o minero pau, o maculelê ou até o samba) ou com as 
variantes internacionais, como o stick fighting ou jogo do pau das plantations haitianas, ou o garrote da Venezuela. Por trás da constatação dessa riqueza, o eterno tema das origens se mostra um problema insolúvel, elencando antecedentes africanos (i.e., o bassula de Angola) ou até ibéricos (o jogo do pau do norte de Portugal), mas sem ser possível emitir qualquer juízo conclusivo.

Numa das seções do filme, intitulada "Diálogos", os historiadores e os mestres capoeiristas cariocas conversam, relembrando as visões da capoeira e do batuque como lugar de crime, na visão da classe média do século XIX, e da sua "normalidade" entre as classes populares. Martha Abreu diz que "a capoeira se civilizou" quando dela foram retiradas a navalha e o pau. A comparação da violência do passado na base da facada com a violência do presente na base da bala é reiterada em várias das falas. Como os filmes anteriores, este finaliza no presente, colocando a necessidade do resgate da tradição do jogo do pau, salientando sua importância na política da identidade cultural e nas possibilidades de seu futuro.

O quarto e último filme da coletânea, Passados presentes: memória negra no sul fluminense (2011, 43 min.), dirigido por Mattos e Abreu, foi produzido a partir de pesquisa iniciada em 2007 e do já referido Acervo UFF Petrobrás Cultural Memória e Música Negra, com montagem e finalização nos anos 2010 e $2011 .^{6}$ O resultado reflete o aprendizado dos filmes anteriores. Formalmente, tem um melhor acabamento técnico e resolve questões narrativas de forma mais eficiente. Por exemplo, aparece no início uma voz em off informando sobre o contexto do Vale do Paraíba, a economia do café e a escravidão; as entrevistas não utilizam legendas; e há um uso de mapas que ajudam o espectador a se localizar melhor. As imagens de transição entre uma entrevista e outra são mais dinâmicas e estéticas, conferindo ao produto um aspecto mais profissional e atrativo. Há, inclusive, experimentação com técnicas narrativas como contar uma história conhecida na região a partir da montagem das vozes de vários dos entrevistados, recurso utilizado em vários momentos.

O trabalho retoma o espírito do primeiro filme da série, com relatos e memórias dos descendentes de escravizados. São lembrados os períodos de engorda a que eram submetidos os africanos na sua chegada, ou o naufrágio do brigue americano Camargo, em 1852, incendiado por seu capitão antes de ser preso com um carregamento ilegal de cativos.

\footnotetext{
Além do LABHOI, participou no projeto o Núcleo de Pesquisa em História Cultural (NUPEHC), da Universidade Federal Fluminense, com patrocínio da FAPERJ e do CNPq (Bolsa Cientista do Nosso Estado, PRONEX Culturas Políticas e Usos do Passado, Edital Humanidades e Pensa RIO, bolsas de Produtividade em Pesquisa e PIBC), além de apoio do Ministério da Cultura através do Pontão de Cultura do Jongo e do Caxambu.
} 
Desta vez, as memórias são alinhavadas, não por meio de uma cronologia ou uma geografia, mas em volta de duas figuras históricas: os irmãos Joaquim e José de Souza Breves, grandes proprietários da região sul do estado do Rio de Janeiro em meados do século XIX. Os membros das comunidades dos antigos domínios desses irmãos, com destaque para Bracuí, no litoral, e Pinheiral, no interior, atuam como protagonistas do filme. Seus depoimentos evocam a crueldade dos senhores - naquela estória do fazendeiro que mandava subir os escravos nos coqueiros para disparar sua carabina, por exemplo -, mas também rememoram como, morrendo sem herdeiros, os Breves deixaram suas terras aos libertos e agregados que nelas moravam. Os membros da equipe visitam vários dos casarões, engenhos e capelas das fazendas dos dois irmãos, quase todos em ruínas, comunicando, de forma metafórica mas também concreta e explícita, a decadência e o colapso daquele universo associado à escravidão.

Nas falas, surgem estórias fantásticas de morcegos, de cobras, de almas penadas de escravos e dos poderes mágicos dos antigos africanos. O jongo, com sua dimensão quase religiosa e "muita milonga", reaparece como prática cultural agregadora, como patrimônio familiar e traço identitário que dá suporte às reivindicações de cidadania. Como os demais documentários da coletânea, a parte final do filme abre espaço para o discurso de pre- servação cultural dos movimentos negros e para a ação política contra o racismo e pela garantia da posse de terras coletivas. $\mathrm{O}$ filme visita a sede do Ponto de Cultura Centro de Referência do Jongo de Pinheral e finaliza com imagens emblemáticas do jongo de Pinheiral celebrado nas ruínas da antiga Fazenda do Pinheiro da família Breves.

A parceria entre historiadores e profissionais de cinema e vídeo torna a coletânea uma das experiências mais instigantes do LABHOI. Diante do discurso historiográfico convencional, ancorado no documento e na escrita textual, a proposta de uma pesquisa e uma narrativa histórica que considera, na sua produção, outro tipo de fontes e de enunciados — orais, sonoros e imagéticos — constitui um saudável desafio.

A "escrita videográfica" dos quatro documentários corresponde ao que os pesquisadores do LABHOI classificam como "escrita intertextual ampliada". Nela "o roteiro se baseia na estrutura da entrevista, organizada segundo o problema levantado pela pesquisa”. Portanto, um primeiro ponto a valorizar é que os filmes são resultado e estão informados por pesquisa historiográfica prévia, o que lhes confere um diferencial em relação a um simples documentário jornalístico. Do ponto de vista da narrativa fílmica, assinada pelo coordenador de filmagem e diretor de fotografia, Guilherme Fernández, e pela coordenadora de edição, Isabel Castro, a coletânea utiliza, no entanto, os recursos clás- 
sicos do documentário cinematográfico, interpolando filmagem de imagens fixas, registros de eventos ao vivo e entrevistas acompanhados pela "música incidental, a trilha sonora, a leitura de depoimentos e a fala dos entrevistados". ${ }^{7}$

Para a produção do registro oral e a consequente inscrição da memória, o LABHOI tem privilegiado a entrevista como a ferramenta básica, desenvolvendo um modelo de "entrevista genealógica", combinando os aportes dos estudos antropológicos sobre parentesco e da experiência africanista da coleta de tradição oral como fonte para a História. Porém, nessa proposta de construção do texto historiográfico audiovisual, cabe refletir sobre a correlação e adequação entre o problema histórico da memória, alvo da pesquisa, e o tempo da narrativa fílmica associado a esse problema.

A memória expressa nos depoimentos do afrodescendente, como a memória do sujeito diaspórico de modo geral, é uma memória fragmentada, episódica, às vezes sincopada, sempre em andamento, em que a lembrança mais distante informa a memória do tempo mais recente e vice-versa. Por outro lado, o artifício da montagem ou da edição fílmica implica uma seleção com intenção narrativa, uma organização temática que não responde necessariamente à dinâmica rememorativa dos sujeitos. A estrutura

\footnotetext{
$7<$ http://www.labhoi.uff.br/node/31>.
}

narrativa, nos dois primeiros filmes, impõe a cronologia linear do tempo historiográfico, partindo da África, passando pelo cativeiro, a Abolição, até o presente. Porém, o tempo da memória negra não acompanha necessariamente essa linearidade, ao contrário, funciona como uma reverberação que se move em múltiplas direções e sentidos. Trata-se de uma memória de luzes e sombras, de silêncios, de interrupções e vazios. Há uma consciência da perda, com a insistência na ideia de que os velhos não falavam, não passavam para os mais novos, mas também uma tenaz reconstrução da cadeia de transmissão: meu pai contava, meu pai me falou, os antigos contavam... O registro videográfico tem a capacidade de mostrar esse esforço vacilante da recordação, ora com o trunfo impiedoso do esquecimento que submerge, ora com a vitória da lembrança que, puxando o fio do primeiro verso, traz o seguinte e, no final, a cantiga toda reemerge. Os fragmentos do passado são acionados, reativados, com uma ordem ou desordem de difícil sistematização. O maior desafio da escrita videográfica seria construir uma narrativa que evocasse ou refletisse a dinâmica errática e imprevisível dessa memória espectral.

Refletindo sobre a memória da escravidão em Serra Leoa, Rosalind Shaw distingue entre a memória discursiva, expressa por meio das falas, e a memória prática, que se perpetua inscrita nos comportamentos, 
nos gestos, nas danças e nos rituais. ${ }^{8}$ Se o primeiro e o último documentários lidam, predominantemente, com a voz dos entrevistados e, portanto, com a memória discursiva, o segundo, Jongos, calangos, e folias, embora continue a privilegiar o busto falante, focaliza também o papel da palavra no contexto ritual, apresentando, assim, um caso de articulação desses dois tipos de memória. Já o terceiro filme, com seu foco no jogo do pau, abriria espaço para uma reflexão sobre o papel do corpo na experiência da dança e do ritual e, portanto, para as formas de memória prática. Porém, como já foi dito, a performance ritual recebe uma atenção discreta no documentário. A possibilidade do "dar a ver" ao espectador, própria do filme etnográfico, é aqui minimizada em favor do "dar a ouvir", ou seu correlato, o "dar a voz".

Os quatro filmes combinam de forma proporcionada o primeiro plano das vozes afrodescendentes com a informação contextual fornecida por cartazes, voz em off e, sobretudo, o diálogo e contraponto dos comentários dos historiadores e pesquisadores. Nesse sentido, cabe destacar o seleto grupo de consultores com que o projeto contou e a participação de vários bolsistas de produção científica. ${ }^{9}$ Porém, o es-

\footnotetext{
8 Rosalind Shaw, Memories of the Slave Trade: Ritual and the Historical Imagination in Sierra Leone, Chicago: The University of Chicago Press, 2002.
}

paço conferido à reflexividade, ou seja, à visibilidade dos produtores do filme no próprio filme, é pouco. Só na metade do primeiro filme se escuta, brevemente, a voz dos entrevistadores, e nos créditos aparecem imagens dos cineastas. O segundo filme incorpora entrevistas com historiadores, e aparecem tangencialmente imagens das diretoras do filme. No terceiro, a voz do entrevistador é mais audível, e Assunção interage com os entrevistados, inclusive se engajando com eles no jogo do pau. No quarto filme, as diretoras Mattos e Abreu aparecem brevemente e, talvez num dos momentos mais etnográficos da coletânea, Geraldo Romão, membro da comunidade do Bracuí, acompanha a equipe de filmagem, apresentando o quilombo e visitando o antigo engenho da fazenda. Essa sequência registra a interação entre filmmakers e filmado e, nela, o filmado é quem dirige e comanda a cena.

Concluindo, cabe destacar o valor historiográfico e o interesse didático de uma coletânea que deve contribuir de forma significativa para a difusão e valorização da memória e do patrimônio cultural dos afrodescendentes nas salas de aulas, tanto

\footnotetext{
9 Entre outros, Ana Lugão Rios (UFRJ), Antônio Carlos Gomes (Instituto de Arqueologia Brasileira), Matthias Assunção (University of Essex, então Professor Visitante no PPGH-UFF), Mônica Leme (UFF) e Robert Slenes (UNICAMP). Os diversos documentários envolveram, além de consultores, diversos bolsistas de Iniciação Científica do $\mathrm{CNPq}$.
} 
do ensino secundário, no contexto das diretrizes nacionais para o ensino de História e Cultura Afro-Brasileira e Africana, como no ensino superior. Nesse sentido, vale lembrar a riqueza dos "Extras" dos DVDs, com registros documentais de performances rituais, informações sobre as regiões visitadas e sobre os participantes do filme, assim como entrevistas com pesquisadores e referências de documentos históricos.

Junto à seriedade historiográfica e a sua vocação didática, Passados presentes apresenta um elevado índice militante, com uma aguçada consciência do papel que a representação do passado e a representação da memória têm na política do presente e na luta pelos direitos de cidadania das populações afrodescendentes. A rica polifonia de vozes desses documentários, aliada à persuasão comunicativa inerente à linguagem cinematográfica, capaz de atingir um público amplo e variado, com certeza deverá contribuir para essa reafirmação política e cultural.

Luis Nicolau Parés lnicolau@ufba.br Universidade Federal da Bahia 